\title{
On memory construction and fictionalization
}

\author{
NGOI Guat Peng (Translated by SHOW Ying Xin)
}

\begin{abstract}
As a response to Ashis Nandy's article about the memory work, this article argues that memories are closely linked to recognition, identity and historical construction while closely connected with local discourse based on post-colonial experiences. In some cases, the construction of memory involves mythical images. The article also addresses the tension between history construction and fictionalization, trying to indicate that some forbidden memory such as those about revolution can be reconstructed in literary writing.
\end{abstract}

KEYWORDS: Memory work, memories of violence, fictional narrative, local discourse

The theme of Nandy's paper is very straightforward - it sets out to read the problematic "memory work," exploring its multiplicities and complicated references. It is like walking through a dense forest. You will discover many secret pathways and signs; they are intricate but at the same time independent and interdependent.

Memories are part of our daily lives; they are active factors within our deep consciousness. They do not work like computer operating systems which only save and archive. Although memories also have the function and form of "archiving," they serve as a "consciousness matrix" which governs human activities in terms of spirituality, feeling, cognition and judgment, and subjected to the political, social and contextual connection. What amazed me the most is the way Nandy unfolds the psychoanalytic approach, which he is good at, on how to access the knowledge system of "memory work." With that, he asked many important questions such as, firstly, what kind of knowledge system is "memory"? What are the cultural forms and structures of memories (which also involve the issue of language with which memories are constructed)? How do we categorize, manage and analyze memories? Secondly, what are the relationships between memory and modern states, developed and developing countries? I would like to share my views from these two aspects, especially on the notion of memory construction and fictionalization. 


\section{Constructing the self of memory and the collective self}

In July 2014, a private session held by "Modern Asian Thought" project Tokyo office took place in Jinze, Shanghai. The topic of the meeting is "National Feeling and International Feeling under East Asian Crisis." We talked about "self and other," about definition, multiplicity, the exchange of different experiences, and about how to think beyond binary oppositions. During the meeting, Mr. Nandy's idea of a "multiple self" became the highlight of our discussion. Professor Law Wing Sang from Hong Kong Lingnan University aptly responded to Nandy's idea: “The so-called 'self' is not a given and unchanging one; instead, it embraces internal division and multiple possibilities. On the other hand, the so-called 'other' is also not a given and unified one. In fact, way before the self and the other met in reality, they have already been constructing each other through imagination."

The reason why I think of Prof. Law's words here is that, Nandy's idea of "collective memories" and "shared memories" suggested in his paper is similarly a way of redefining "collective self." In other words, memories are a "medium" to construct any kind of "self." The reason why the self splits into the multiple form of national self and collective self lies in the manipulation of memory work and how the "other" is constructed. In most cases, memories are closely linked to recognition, identity and historical construction. "Memories" can also serve as critical perspectives or resistant consciousness which help people obtain proper "self-consciousness" when facing unjust historical narratives. However, when people need to construct collective memories or locally based memories that can form a sense of connection among them, a particular kind of "local discourse" and the ritualistic cultural narratives become upmost important.

"Local discourse" refers to the locals' interpretation of local objects and events, which further forms a prevailing perspective through which things are accounted for and viewed. It bears the crucial responsibility of passing down local memories, possessing the cultural function to repair fault memories, and serves as a representation of local traditions. Nevertheless, in tradition, it seems that documentations are the only accepted evidence when it comes to history. But from the anthropological point of view, memories serve as equally valid information in terms 
of reconstructing the past, as they themselves are important cultural choice. Let me give an example here. Folk-cultural scholar Zhao Shiyu (2002) once mentioned about the folklore Taiyang Jing (Book of Sun) in his essay "The Birthday of Sun: Southeast Coast's Historical Memory of Emperor Chongzhen." According to the Book of Sun, March 19th is the birthday of Sun God. But in fact, the book was edited by Emperor Chongzhen's third daughter, as an attempt to mourn the death of her father and the lost of her nation. The claimed Sun God's birthday became a political metaphor with which the truth is to be hidden from the Qing emperors. In China's southeast coastal regions, this metaphor has been transformed into a symbolic asset endowed with historical memories. But when it travels to different regions, the symbol of "March 19th" connects with the local socio-history and is transformed into various local discourses.

In postcolonial experiences where daily memories are connected with local discourse, the imagination and building of "heroic" characters has been a common practice, as memories become the crucial agency with which identity is confirmed. For example, in Sarawak, there is a gold-mining town called Bau (Shi long men) where Chinese settlers worked as miners during the British colonial period under the rule of James Brooke. The Chinese workers were exploited by the British gold-mining company, and an uprising finally broke out. During that time, a person named Liu Shan Bang was characterized as an "anti-colonial hero" in the stories passed down by locals as part of their memories. He was even deified as a guardian-like god in the area of Siniawan. It is not uncommon in many places that human characters are deified as god, but in Siniawan, such transformation further involves the resistance to colonial history and people's psychological need of an anti-colonial hero. Liu Shan Bang's images, fused by people's memories passed down as local folklores, differ entirely from those obtained by historians through analyzing colonial archive or historical documents. For the latter, Liu Shan Bang is merely a fictional character constructed by memories.

Stories of Sun God's Birthday and Liu Shan Bang show us that the construction of memory involves mythical images or the appropriation of religious connotations, supported by a set of discourses and narrative norms. Meanwhile, we came to understand that in the tension between construction and fictionalization, when we acknowledge that passing memories down would eventually fuse a mnemonic which serves as a "structure of fusion," the memories of self will then belong to the collective, 
and further become parts of the collective self.

\section{Issues of memory, failure, violence and "nation"}

It touched me very much when Nandy quoted George Orwell in his essay, that "memory management is a crucial part of modern statecraft." How to choose a mode of memory, as well as how it is embedded into the structure of a society, often involve the process of contention and selection. In a postcolonial society, when it comes to writing its own history, many of the stories to be written involve resistance, accompanied with traumatic memories which demand justice. However, the "firewall" accompanying traumatic memories is not necessarily a result of the pressure from outside, as how we normally consider the contention of social memories as the struggle between the authority and ordinary people, which in some cases is true. However, we should not neglect the crucial factor of psychological suppression constructed by fear, unease, anxiety, and uncertainty. Memory does not always carry an aim, and its outline and mode of cognition are constantly decided in relation to the enemy we assign and shape in our heart.

In the historical context of anti-colonialism and anti-imperialism in Singapore and Malaysia, the memories of revolution are the memories of a Red symbol. In the case of people's memories of the Malayan communists' revolution, for instance, whether the latter are in written records, oral histories or fictional works, a dense mnemonic network has to be created in order to tie them together. One of the examples is the set of configuration of "jungle and hunger" or "love and desire." Sometimes, memories of revolution have to be transformed into a "fictionalized" literary form so as to dig into deeper psychological state of the revolutionists. For example, literary narratives are also a way of constructing memories in a broad sense. As indicated in a recently published short story "Memorandum of the People's Republic of Malaya” by $\mathrm{Ng} \mathrm{Kim} \mathrm{Chew} \mathrm{(2013),} \mathrm{issues} \mathrm{of} \mathrm{memories} \mathrm{are} \mathrm{aptly} \mathrm{presented} \mathrm{in} \mathrm{a} \mathrm{psychoanalytic} \mathrm{way.}$

The story depicts the return of a communist fighter Lao Jin to his hometown after living in the jungle for 40 years. He never contacts other comrades since his return. Fifteen years later, he was found dead nakedly, with his body embedded in a tree hole emanating pungent smell of rotten flesh, surrounded by flies. A local newspaper reported that "Well-known Communist xxx Died Bizarrely in Hometown's Tree" —a 
lone powerful line bearing witness to the absurd and decaying death of a communist fighter.

The decaying body of Lao Jin is to a certain extent related to his collapsing mental state after he left the jungle. When revolutionary ideals lost their solid base, the dream of Utopia disillusioned, one has no choice but to confront one's own past upfront; this is not only an issue for Lao Jin in the story, but also for many Malayan communists in reality. In the story, Lao Jin often immersed himself in the feeling of lost, the sense of failure.

But in fact, he was always preoccupied, especially in those 20 years after the independence. He became very anxious. Now that Malaya has gained independence, what should we fight for then? For the dignity of Malayan communists, or for an acknowledgment in history?..... At the same time, he was also under harsh criticism for writing an unrealistic utopian novel with heavy defeatist sentiment, titled A Record of the People's Republic of Malaya.

Such a scrutinization shows the peeling-off of "self" from the collective in the case of Malayan communists. How do we recall the defeated battle and face the painful reality? Literary fiction speaks for the suppressed self, exploring the most fundamental in memories. The death of Lao Jin seems to indicate that when the "self" is separated from the "collective," memories of the self have nothing to cling to. What follows is the withering of mind, taking place a lot faster than that of one's physical body. Although fiction is not equal to history, unexpectedly, fictional narratives in effect compensate the memories.

Now, I would like to talk about the memories of violence. In a society such as Malaysia that celebrates multiethnic and multicultural history as well as living experiences, we not only need to construct collective self by virtue of the collective or common memories, but also need an "ethnic-self" which would help to liberate the suppressed trauma or shame the ethnic group bears; especially when the state interferes in people's memories in order to decide how the past should be interpreted. For instance, the racial conflict occurred on May 13, 1969 has been a mnemonic predicament for all ethnic groups in Malaysia. Neither the media nor ordinary people are allowed to openly discuss the conflict. Until now, the rights of interpreting the memories are still at the 
hands of the authoritative power.

In Hong Kong, I once interviewed a witness of May 13. He is a retired professor now, and had at the end of the 1960s been working as a young French teacher at the Alliance Francaise Malaysia. On May 13, he finished his classes at the center and walked out with his students. He saw a group of armed Malays across the street, and suddenly, one of his Chinese students was injured by a spear and collapsed right in front of him. He later went on the streets with a list of his students' names in hand, trying to make sure if they are safe. He recalled the chaotic situation back then, when people set things on fire everywhere. He said, "I saw fire," a simple yet powerful line that took us vividly back to the burning scene. But he also emphasized that after the May 13 incident, many of the Malays protected their Chinese friends from being hurt, therefore it's a complicated situation that can't be interpreted in an over-simplified way.

Historian Eric J. Hobsbawn (2002) once cautioned that, when it comes to dealing with histories that have been covered up or distorted by the authorities that be, led by questions and presumptions provided by the interviewers, those who provide their counter memories often look for only those they want, instead of those cover the general history as a whole. Such memories can only be treated as data, and is something that should be avoided in making oral histories. How striking Hobsbawn's warning is. However, no History can survive without memories and experiences. And that is what makes the memory work precious.

\section{References}

Hobsbawn, Eric J. 2002. 論歷史 [On History]. Translated by Huang Yuwen 黃煜文. Taipei: Maitian 麥田.

$\mathrm{Ng}$, Kim Chew 黃錦樹. 2013. 南洋人民共和國備忘錄 [Memoirs of The People's Republic of the South Sea]. Taipei: Maitian 麥田.

Zhao, Shiyu 趙世瑜. 2002. 狂歡與日常一明清以夾的廟會與民間社會 [Festivity and the quotidian: temple fairs and society since the Ming and Qing dynasties]. Beijing: Joint Publishing 三聯.

\section{Special terms}

Emperor Chongzhen 崇禎皇帝

Jinze 金澤 
Lao Jin 老金

Liu Shan Bang 劉善邦

Shi long men 石隆門

Siniawan 新堯灣

Taiyang Jing 太陽經

\section{Author's biography}

Ngoi Guat Peng 魏月萍 is Assistant Professor at the Division of Chinese, School of Humanities of Social Sciences of Nanyang Technological University, Singapore. She received her $\mathrm{PhD}$ degree from the School of Arts and Social Sciences at National University of Singapore. She is currently a researcher of the Inter-Asia School, and her research interest includes Chinese Intellectual History, Neo-Confucianism, and Religion Syncretism. She is also concerned about the knowledge production in Malaysian history, the literature and culture.

Contact e-mail: gpngoi@ntu.edu.sg

\section{Translator's biography}

Show Ying Xin 蘇穎欣 is PhD Candidate at the School of Humanities of Social Sciences, Nanyang Technological University, Singapore. She received her BA in Foreign Languages and Literature from National Sun Yat-sen University, Taiwan. Her areas of interest include Modern Chinese and Sinophone literature, Anglophone literature, cultural criticisms, Asian thoughts and Southeast Asian studies.

Contact e-mail: show0001@ntu.edu.sg 